\title{
A Fully Synthetic "Phage-Like" System II: Synthesis and Live Cell Screening of Combinatorial Libraries of Peptides on Sub-Cellular Sized Microspheres
}

\author{
Raz Khandadash $^{1}$, Shirly Partouche ${ }^{1}$, Aryeh Weiss ${ }^{3}$, Shlomo Margel ${ }^{2}$ and Gerardo Byk ${ }^{*}, 1$ \\ Department of Chemistry ${ }^{l, 2}$, Laboratory of Nano-Biotechnology ${ }^{l}$ and School of Engineering ${ }^{3}$, Bar Ilan University, \\ Ramat Gan 52900, Israel
}

\begin{abstract}
Herein we present a new application of a recently demonstrated fully synthetic "phage-like" system for screening of combinatorial mixtures in a live cell assay. The new application includes the direct synthesis of peptides and combinatorial libraries on $2 \mu \mathrm{m}$ cross-linked mono-dispersed microspheres bearing a panel of fluorescence tags. Their characterization using classical chemical analysis as well as biological recognition of the synthesized sequences on the microspheres by specific antibodies, demonstrate the robustness of the system. Two biased positional combinatorial peptide libraries derived from peptide DUP-1 were synthesized and screened for affinity to prostate cancer PC-3 cell line as compared to DUP-1, a peptide with good affinity for this cell line. The best sub-library was deconvoluted and mixtures of deconvoluted peptides on microspheres were screened for identifying the sequences with the best affinity for cells. The best peptide, DUP- $1_{(1-12)}{ }^{2}$ Ala with high affinity for PC-3 cells, was individually synthesized and validated in an independent binding assay. Finally, the cellular fate of DUP- $1_{(1-12)}{ }^{2} \mathrm{Ala}$ in PC-3 cell line is demonstrated using confocal laser scanning microscopy. Overall, these results demonstrate that the synthetic phage-like system recently assessed for screening mixtures of small organic molecules, can be also used for synthesis and screening of combinatorial libraries of peptides in live cell assays.
\end{abstract}

Keywords: Screening, microsphere, phage-like particle, peptide, Ugi.

\section{INTRODUCTION}

High throughput screening (HTS) of small molecules is likely based on the panning of candidate molecules (organic small molecules, peptides) for binding to isolated target proteins (such as enzymes or antibodies), usually anchored to a solid matrix that allows automation of the process, thus providing high throughput. HTS brought about an exponential growth in the number of detected biologically relevant small molecules ("hits"). On the other hand, current HTS systems do not face pharmacokinetic (PK) parameters such as bioavailability, stability and selectivity, which are essential for transforming the identified in vitro "hits" into in vivo "leads". Therefore, it is of great importance to develop new screening techniques in live cells and in vivo aimed at facing and solving problems related to pharmacokinetic barriers.

We have recently assessed a fully synthetic "phage-like" system based on carrier supported mixtures, aimed at identifying peptides or small organic molecules with high affinity for specific cell types in a live cell assay [1]. We called the system "phage like" because the main elements found in the phage display technique were recreated by synthetic elements. In this phage like system, a mixture of different ligands anchored to sub-cellular sized microspheres is added to a cell line of interest. After incubation and washing procedures similar to those used in phage display peptide

*Address correspondence to this author at the Department of Chemistry, Bar-Ilan University, Ramat-Gan 52900, Israel; Fax: +972-3-7384053; Tel: +972 3 5318325; E-mail: bykger@mail.biu.ac.il screening, bound small molecules are detected by flow cytometry based on the differential fluorescence intensities of the different microspheres. A major interest of our new synthetic phage-like system is to screen small molecules, unnatural peptides and peptides longer than 12 amino acids that cannot be expressed in phage systems for screening [24]. In a first proof of concept study [1] we have assessed the system for a library of small molecules obtained by the known Ugi reaction. The Ugi-library was tethered on the tagged microspheres and screened as mixtures of 4 small molecules. A small molecule Rak-2 was identified and validated by an independent binding assay, and cellular internalization of this molecule was clearly shown using confocal microscopy. In the present work we have expanded the use of the phage like system to the synthesis and screening of biased positional combinatorial libraries.

Together with recently published approaches which used microscopy for identifying cellular multiplexing of colored nano-particles in live cells [5], our results contribute another step towards developing and transforming live cell panning into a high content screening system (HCS), where a mixture of ligands bound to appropriately tagged particles is added to cells and the interacting ligands are identified through specific tags. A live cell screening method for panning mixtures of molecules bound to particles is an important step towards in vivo combinatorial screening in animal models, which will need the development of additional histological methods to trace the presence of particle-bound ligands in tissues of interest. 


\section{MATERIALS AND METHODS}

\section{General}

FACS was conducted using FACS Calibur flow cytometer (Becton-Dickinson) equipped with a 488-nm argon laser, results and data acquisition were analyzed using software CellQuest and a Power Macintosh G4. HPLC was performed on Waters Gradient System equipped with a 717Plus auto sampler, a Waters 600 intelligent pump, and a Waters 996-photodiode array detector; the system was piloted with Millennium software from Waters. Selected wavelengths for chromatograms were $220 \mathrm{~nm}$ and $254 \mathrm{~nm}$. Mobile phases were (A) $\mathrm{H}_{2} \mathrm{O}(0.1 \%$ TFA) and (B) $\mathrm{MeCN}$ $(0.08 \%$ TFA). Separation condition for analytical analysis was as follows: Column Chromolith Performance (from Merck) RP-18e 100-4.6 nm, gradient $\mathrm{H}_{2} 0 / \mathrm{MeCN}$, Gradient a [A/B]: 1 min [100/0], 1-8 $\min [0 / 100], 8-11 \min$ [0/100], $11.1 \mathrm{~min}[100 / 0]$; flow $=6 \mathrm{~mL} / \mathrm{min}$.

Preparative HPLC was performed on a Gilson's HPLC System with a Gilson 321 pump, and a Gilson 155 UV/VIS HPLC detector with option two wavelengths, manual injector and fraction collector Gilson FC 204; the system was piloted with Unipoint LC system software from Gilson. Mobile phases were (A) $\mathrm{H}_{2} \mathrm{O}(0.1 \%$ TFA) and (B) $\mathrm{MeCN}$ $(0.08 \%$ TFA). Separation condition for preparative analysis was as follows: separation was conducted using Column $(250 \times 22 \mathrm{~mm})$ Vydac C18 reversed phase: Gradient b: gradient $\mathrm{H}_{2} 0 / \mathrm{MeCN},[\mathrm{A} / \mathrm{B}]: 3 \mathrm{~min}$ [100/0], 3-40 $\min$ [0/100], 40-45 $\mathrm{min}[0 / 100]$, flow $=30 \mathrm{~mL} / \mathrm{min}$. After purification, the purity of compounds was more than $95 \%$. as determined using gradient $a$. MS analyses was conducted using ESI (electron spray ionization) mass spectrometry on a Q-TOF low-resolution micromass spectrometer (Micromass-Waters, Corp.), HR-MS was conducted using AUTOSPECFISSONS VG (Micromass) high-resolution mass spectrometer under DCI (desorption chemical ionization) conditions $\left(\mathrm{CH}_{4}\right)$ or high-resolution MS-MALDI-TOF spectra with an Autoflex TOF/TOF instrument (Bruker, Germany). 2,5Dihydroxybenzoic acid (DHB) was used as a matrix.

Microscopy was conducted using a confocal inverted microscope Olympus FV-1000/IX-81, with 40x/NA=0.9 air objective. All image processing was done in ImageJ [6]

All solvents were analytically pure grade and were used without further purification. HPLC water was purchased from Beit Dekel Ltd., Israel. HPLC acetonitrile was purchased from BioLab Ltd., Jerusalem, Israel. RPMI 1640 with glutamine, $0.25 \%$ Trypsin\&EDTA solution and Penicillinstreptomycin solution were purchased from Biological industries Ltd., Haemek, Israel. Foetal Boving Serum (FCS) was purchased from invitrogen Ltd. Fmoc protected Amino acids, 1-Hydroxybenzotriazole (HOBt) and Benzotriazole-1yl-oxy-tris-(dimethylamino)-phosphonium hexafluorophosphate (BOP) were purchased from GL Biochem (Shanghai) Ltd. Boc-21-amino-hexaoxaheneic osanoic acid (Boc$\left.(\mathrm{PEG})_{6}-\mathrm{COOH}\right)$ (code No. BA19206) was purchased from NeoMPS, Inc. Ethylenediaminetetraacetic acid (EDTA) and $\mathrm{N}$-methyl morpholine (NMM) were purchased from Acros Organic, Israel. Fluorescein isothiocyanate(FITC) was purchased from Sigma Aldrich. Sulforhodamine B was purchased from New biotechnology Ltd, Israel.

\section{Cell Culture}

The human prostate carcinoma cell line PC-3 (from American Type Culture Collection, Manassas, VA) were generously donated by Prof. Zelig Eshhar from Weizman Institute, Rehovot/Israel. Cells were cultivated at $37{ }^{\circ} \mathrm{C}$ in a $5 \% \mathrm{CO}_{2}$ incubator (Water-Jacketed,US Autoflow Automatic $\mathrm{CO}_{2}$ Incubator manufactured by NuAire, Inc.) in RPMI 1640 with Glutamine supplemented with $100 \mathrm{IU} / \mathrm{ml}$ Penicillin, 100 $\mu \mathrm{g} / \mathrm{ml}$ Streptomycin and $10 \%$ FCS.

\section{MICROSPHERES}

The synthesis functionalization, tagging and linker introduction on the microspheres were conducted as previously described [1].

\section{1- General Procedure for Peptide and Libraries Syn- thesis on Microspheres}

Microspheres bearing 10\% mol Fmoc-Rink linker in $1 \mathrm{ml}$ DMF (0.2 g, $0.048 \mathrm{mmol})$ were uniformly dispensed into 10 wells of a 96 wells polypropylene Pall microplate with 0.45 $\mu$ filters. A solution of $20 \%$ piperidine in DMF was then added and the microplate was stirred with an orbital shaker at $\mathrm{rt}$ for 20 minutes. The microspheres were washed alternately with DMF $(0.2 \mathrm{ml} \times 3)$, i-PrOH $(0.2 \mathrm{ml} \times 3)$ and used directly for the peptide/library synthesis using Fmoc chemistry. Each well contains the starting unprotected microspheres $(0.02 \mathrm{~g}, 0.0048 \mathrm{mmol})$, the Fmoc-amino acids corresponding to the sequence DAEFRHDSGYEVHH (amyloid- $\beta$ peptide), EQKLISEEDL (c-myc peptide) or the appropriate kinetic mixture of 12 amino acids for the biased combinatorial libraries $(0.0484 \mathrm{mmol})$, BOP reagent $(0.021$ gr, $0.0484 \mathrm{mmol})$, hydroxybenztriazole (HOBT) $(0.007 \mathrm{gr}$, $0.0484 \mathrm{mmol})$ and $\mathrm{N}$-methyl morpholine $(10 \mu \mathrm{l}, 0.096$ $\mathrm{mmol}$ ) in DMF. The reaction was stirred at $\mathrm{rt}$ for $2 \mathrm{~h}$ under orbital stirring, followed by alternate washings with DMF $(0.2 \mathrm{ml} \times 3)$ and i-PrOH $(0.2 \mathrm{ml} \times 3)$. After each synthetic step Fmoc group was deprotected using $20 \%$ piperidine in DMF. The wells were washed by multipipetor simultaneously with DMF $(0.2 \mathrm{ml} \mathrm{x} 3)$ and i-PrOH $(0.2 \mathrm{ml} \mathrm{x} 3)$. Peptides were deprotected in $1.5 \mathrm{ml}$ tubes during $2 \mathrm{~h}$ at $\mathrm{rt}$ using $0.5 \mathrm{ml}$ of a mixture composed of TFA: TIS: $\mathrm{H}_{2} \mathrm{O}$ (95\%: $2.5 \%: 2.5 \%$ ). Microspheres were centrifuged and washed with THF. The supernatant containing the cleaved peptide was removed to glass vials, evaporated, washed with ether and analyzed using MS and HPLC (HPLC of c-myc and amyloid- $\beta$ peptides are available in the supporting information). The peptides-microspheres were thoroughly washed with PBS and were used in the screening assays.

\section{2- ELISA Assays of Peptides c-myc-microspheres and Amyloid $\beta$ N-terminal-microspheres for Validation of the Synthesis on the Microspheres}

Experiments were carried out three times. In the initial step, the c-myc peptide-microspheres $1 \mathrm{mg}$ in $0.2 \mathrm{ml} \mathrm{PBS}$ were dispersed into 7 wells of a microtiter plate and the $\beta$ amyloid peptide microspheres $1 \mathrm{mg}$ in $0.2 \mathrm{ml}$ PBS were dispersed into 3 wells of a microtiter plate.

Both microspheres were first blocked with PBS blocking solution for $1 \mathrm{~h}$ at $37^{\circ} \mathrm{C}$ followed by washings with $\mathrm{PBS}$ 
Tween three times. Then two development systems were used depending on the tag we wished to monitor:

For developing c-myc microspheres they were incubated with a monoclonal mouse anti-human c-myc antibody (code No. M3570, DAKO) at concentration 1:50 for $2 \mathrm{~h}$ at $37^{\circ} \mathrm{C}$.

For developing amyloid- $\beta$ microspheres they were incubated with rabbit (polyclonal) anti-human amyloid $\beta$ nterminal antiserum (code No. AHB0121, Biosource laboratories) at concentration $1: 200$ for $2 \mathrm{~h}$ at $37^{\circ} \mathrm{C}$.

Both microsphere batches were then washed with PBS/ Tween three times followed by incubation with EnVisionTM+/HRP, Dual Link Rabbit/Mouse (code No. $\mathrm{K} 406311$, DAKO) for $1 / 2 \mathrm{~h}$ at $37^{\circ} \mathrm{C}$. Washings with PBS/ Tween washing solution, was followed by adding a freshly prepared chromogen-substrate solution (a $2: 1(\mathrm{v} / \mathrm{v})$ mixture of $1 \mathrm{mg}$ TMB in $10 \mathrm{ml}$ citrate buffer and $2 \mu \mathrm{L} \mathrm{H}_{2} \mathrm{O}_{2}(30 \%)$ was added and incubated for $30 \mathrm{~min}$ in dark). The enzyme reaction was stopped by addition of $1 \mathrm{M} \mathrm{H}_{2} \mathrm{SO}_{4}$ to each well. After centrifugation the microspheres were analyzed by ELISA.

\section{3- General Procedure for Flow-Cytometry Screening of Microsphere Mixtures}

Individual microspheres-ligands or biased combinatorial libraries were counted using a hemacytometer for a better distribution of the ratios in the set-mixtures. A mean of $5 \times 10^{5}$ microspheres of individual ligands per $\mathrm{ml}$ were necessary for each well. Thus the different ligand-microspheres were mixed to obtain the corresponding mixture sets. The different sets were dispersed in PBS in FACS tubes, and analyzed by FACS to evaluate their exact initial ratio. Then, $1 \%$ BSA was added to the suspensions, which were added in triplicates onto a six-well plate containing PC-3 cells seeded to $75 \%$ confluence and where incubated for 30 minutes at $37^{0} \mathrm{C}$. Subsequently, the cells were washed with cold PBS $(1 \mathrm{ml} \mathrm{x} 10)$ and lysed using a solution of $0.3 \mathrm{M} \mathrm{NaOH}$ for 7 minutes. The remaining microspheres were centrifuged at $5700 \mathrm{rpm}(4 \mathrm{~min})$ and washed three times with buffer PBS/ $2 \%$ SDS. Microspheres were suspended on buffer PBS/ $2 \%$ SDS and were shaken for $3 \mathrm{hr}$. The ratio between the different populations was measured again by FACS analysis and each compound was ranked using equation (1). Experiments were repeated 3 times.

\section{4- Peptide Synthesis for Validation Studies}

\section{DUP-1 ${ }_{(1-12)}^{2}$ Ala (FAPNRAQDYNTN-amide) Peptide}

It was synthesized by solid-phase Fmoc strategy; the synthesis was performed using $0.25 \mathrm{mmol}$ Rink Amide-AM resin $(0.52 \mathrm{mmol} / \mathrm{g}$ loading). The resin was introduced in the ABI-431A peptide synthesizer and all Fmoc-amino acids were coupled using the $\mathrm{DCC} / \mathrm{HOBt}$ protocol from the company (4-fold excess of the Fmoc-amino acid, 90 min per coupling). The peptide was cleaved from the resin with a mixture of TFA: TIS: $\mathrm{H}_{2} \mathrm{O}(95 \%: 2.5 \%: 2.5 \%)(5 \mathrm{ml})$ yielding the crude DUP- $1_{(1-12)}$ Ala peptide which was precipitated and washed with cold ether $\left(5 \mathrm{ml} \mathrm{X} \mathrm{5)}\right.$. The crude DUP-1 $1_{(1-}$ 12) ${ }^{2}$ Ala (385 mg) was purified by preparative HPLC (gradient b) and lyophilized to give $170 \mathrm{mg}$ of the peptide product as a white solid. HPLC analysis: $t_{R}=3.22 \min$ (gradient a); MS analysis: HRMS (MALDI) $m / z$ calcd for $\mathrm{C}_{60} \mathrm{H}_{89} \mathrm{~N}_{20} \mathrm{O}_{20}$ $=1409.6557$; found 1409.650 .

\section{DUP-1 and 15-mer}

These peptides were synthesized and characterized as described previously [1]. DUP-1 analysis: HPLC analysis: $\mathrm{t}_{\mathrm{R}}=3.12 \mathrm{~min}$ (gradient a); MS analysis: HRMS (MALDI) $m / z$ calcd for $\mathrm{C}_{63} \mathrm{H}_{96} \mathrm{~N}_{23} \mathrm{O}_{20}=1494.7196$; found 1494.715 .

15-mer analysis: HPLC analysis: $t_{R}=4.38$ min (gradient a); MS analysis: HRMS (MALDI) $\mathrm{m} / \mathrm{z}$ calcd for $\mathrm{C}_{96} \mathrm{H}_{134} \mathrm{~N}_{27} \mathrm{O}_{22}=2017.0191$; found 2017.004.

\section{(FITC- ${ }^{13}$ Lys)DUP-1 $(1-12){ }^{2}$ Ala for Microscopy Studies}

To label DUP- $1_{(1-12)}{ }^{2}$ Ala peptide for confocal microscopy experiments, the peptide was synthesized exactly as described above but starting the synthesis with Fmoc-Lys(Mtt)$\mathrm{OH}$ at the C-terminal as in previous studies [7]. The first amino acid was manually loaded using BOP reagent (4-fold excess, $2 \mathrm{~h}$ ). After peptide synthesis in the peptide synthesizer, the resin $(0.1 \mathrm{mmol})$ was taken out of the synthesizer reaction vessel and the Mtt protecting group on the lysine side chain was removed by gentle mixing in $4 \mathrm{~mL}$ of a 1:5:94 mixture of TFA/TIS/DCM for two minutes and was followed by removal of the solution by filtration and a resin wash with DCM. This process was repeated six times. The clear TFA solution became yellow when added to the resin and this yellow color was less intense with each subsequent cycle [8]. Ninhydrin test was positive. Then, the resin was swollen with $3 \mathrm{~mL}$ DMF. TEA $(160 \mu \mathrm{L}, 1 \mathrm{mmol})$ and FITC (98 $\mathrm{mg}, 0.25 \mathrm{mmol}$ ) were added and the resin was shaken for $2 \mathrm{~h}$ in an orbital shaker. Then, the resin was washed alternately with DMF/iPrOH. Ninhydrin test was negative. Then, the peptide was cleaved, washed and purified as described above. HPLC analysis: $\mathrm{R}_{\mathrm{t}}$ ) $3.82 \mathrm{~min}$ (gradient a). MS analysis: HRMS (MALDI) $m / z$ calcd for $\mathrm{C}_{87} \mathrm{H}_{112} \mathrm{~N}_{23} \mathrm{O}_{26} \mathrm{~S}_{1}$ 1926.7864; found 1926.784 (FITC- ${ }^{13}$ Lys) DUP-1 peptide was synthesized and characterized as described previously [1]. HPLC analysis: $\mathrm{R}_{\mathrm{t}}$ ) $3.76 \mathrm{~min}$ (gradient a). MS analysis: HRMS (MALDI) $m / z$ calcd for $\mathrm{C}_{90} \mathrm{H}_{119} \mathrm{~N}_{26} \mathrm{O}_{26} \mathrm{~S}_{1} 2011.8504$; found 2011.838 .

\section{5- General Procedure for Hit Validation by a Cell Based Flow Cytometry Assay}

PC-3 cells were grown in the incubator to $70 \%-80 \%$ confluence for 3 days at $37^{\circ} \mathrm{C}$ and $5 \% \mathrm{CO}_{2}$. Then, cells were washed with $3 \mathrm{ml}$ PBS and detached with $5 \mathrm{ml}$ of $1 \mathrm{mM}$ EDTA in PBS for 40 minutes in the incubator. Mixtures were transferred to tubes and centrifuged for 8 minutes at $1200 \mathrm{rpm}$. The cells were counted, re-suspended at a density of $10^{6}$ cells / $\mathrm{ml}$ in RPMI (without FCS) and centrifuged for 5 minutes at $1200 \mathrm{rpm}$ and the supernatant was discarded. Cells were placed in $1.5 \mathrm{ml}$ tubes. In parallel, unlabeled DUP-1, DUP-1 ${ }_{(1-12)}{ }^{2}$ Ala, 15-mer and pegylated Rak-2 [1] were dissolved in fresh RPMI containing $1 \%$ BSA at different concentrations (from $50 \mathrm{nM}$ to $0.6 \mathrm{mM}$ ). $250 \mu \mathrm{l}$ of each concentration were transferred to the $1.5 \mathrm{ml}$ tubes containing the cells and pre-incubated for $40 \mathrm{~min}$ at $37^{\circ} \mathrm{C}$ in the orbital shaker. Then, $250 \mu \mathrm{l}$ of a $2 \mu \mathrm{M}$ solution of FITClabeled DUP-1 in 1\% BSA was added to each tube and incubated for $10 \mathrm{~min}$. The cells were transferred to FACS tubes and analyzed by flow cytometry without further 
processing. The measurement stopped when 20000 gated events were counted. The geometric means of fluorescence in channel FL-1 of the gated cells were obtained using the Cell-Quest software. Mean values \pm S.E.M., $n=3-5$.

6- Cell Binding and Penetration Validation of DUP$1_{(1-12)}{ }^{2}$ Ala as Compared to DUP-1 Using Microscopy

PC-3 cells were trypsinized, counted and cultured subconfluently ( $4 \times 10^{5}$ cells per dish) onto $35 \mathrm{~mm}$ glass-bottom culture dish (MatTek Co., Ashland, MA, USA) for $24 \mathrm{hr}$. On the day of experiment, the medium (RPMI 1640) was replaced with $2 \mathrm{ml}$ of fresh medium. FITC- ${ }^{13}$ Lys-DUP-1 or FITC- ${ }^{13}$ Lys -DUP- $1_{(1-12)}{ }^{2}$ Ala and Sulforhodamine B were dissolved in RPMI-1640 (without FCS) at $100 \mu \mathrm{M}$. $20 \mu \mathrm{L}$ of each peptide was added to the cells to reach a final concentration of $1 \mu \mathrm{M}$ in the medium. Cells were incubated for $1 \mathrm{hr}$. Then, the cells were washed with fresh medium (without FCS) $(5 \times 2 \mathrm{ml})$. For measurement of fluorescence, 2 $\mathrm{ml}$ medium was added to the cells and they were immediately transferred to the microscope. Then, $20 \mu \mathrm{L}$ of the 100 $\mu \mathrm{M}$ sulforhodamine $\mathrm{B}$ solution were added to the dish and the cells were imaged with an Olympus FV-1000/IX-81 confocal inverted microscope equipped with a temperaturecontrolled stage that was kept at $37{ }^{\circ} \mathrm{C}$. All images were acquired with a $40 \mathrm{X} / \mathrm{NA}=0.9$ air objective. The confocal aperture was $110 \mu \mathrm{m}$. The excitation wavelengths were 488 $\mathrm{nm}$ for FITC and $561 \mathrm{~nm}$ for the SRB. The FITC was detected using a dichroic mirror SDM-560 and band-pass emission filter (BA 505-545nm), while a dichroic mirror SDM-640 and band-pass emission filter (BA 585-615nm) were used to detect SRB. FITC and SRB were imaged in sequential mode, to avoid crosstalk between the two fluorescence channels. Nonconfocal DIC transmitted light images were acquired simultaneously with the fluorescence confocal images. Images were collected as stacks along the z-axis of cells with $2 \mu \mathrm{m} /$ slice ( $\sim 6$ slices per specimen). Images were processed using ImageJ.

\section{RESULTS AND DISCUSSION}

Since the phage like system has been extensively explained in a previous work [1], we describe here the most important features. Briefly, the system is composed of monodispersed cross-linked $2 \mu \mathrm{m}$ microspheres (Fig. 1, step 1) bearing a panel of intensity-level fluorescent labels (Fig. 1, step 2) on which libraries of ligand candidates or combinatorial libraries are either directly synthesized or linked after synthesis (Fig. 1, step 3). Each fluorescence intensity represents a specific ligand or a specific sub-library. The subcellular size of the microspheres allows their incubation with cells grown on microplates (Fig. 1, step 4) and consequently their interactions with cells can be measured after repeated washings (Fig. 1, step 5) and cells lysis. The remaining cell lysates contain those microspheres with significant affinity for the cells, either bound to the cell surface or internalized prior to lysis. These microspheres are visualized by flowcytometry and ranked by comparing the FACS plots to an appropriate control in the mixture (Fig. 1, step 6) as described previously [1]. The model peptide DUP-1, which is a known high affinity ligand for PC-3 cells [7] from a phage display library (with unknown cellular target), was synthesized on tagged microspheres and used as a standard positive control in all the mixtures.

\section{RELIABLE SYNTHESIS OF PEPTIDES CAN BE PERFORMED ON THE MICROSPHERES AS DEM- ONSTRATED BY A BIOLOGICALLY PERTINENT ASSAY}

This part of the system was validated previously by the synthesis and characterization of DUP-1 and 15-mer peptides for the direct synthesis of peptides on the microspheres [1]. Herein we use another way for assessing the correct synthesis of peptides on the sub-cellular sized microspheres using a biologically relevant analysis instead of the classical chemical characterization: the use of a biologically functional assay based on specific antibodies directed against the synthesized peptides, this bio-characterization proves that the synthetic peptide not only has the correct sequence, but it is also in good contact with the biological media so that it can adopt the appropriate conformation for biological recognition. Feasibility was demonstrated by the synthesis of 2 new peptides: 1- c-myc peptide and 2- N-terminal amyloid- $\beta$.

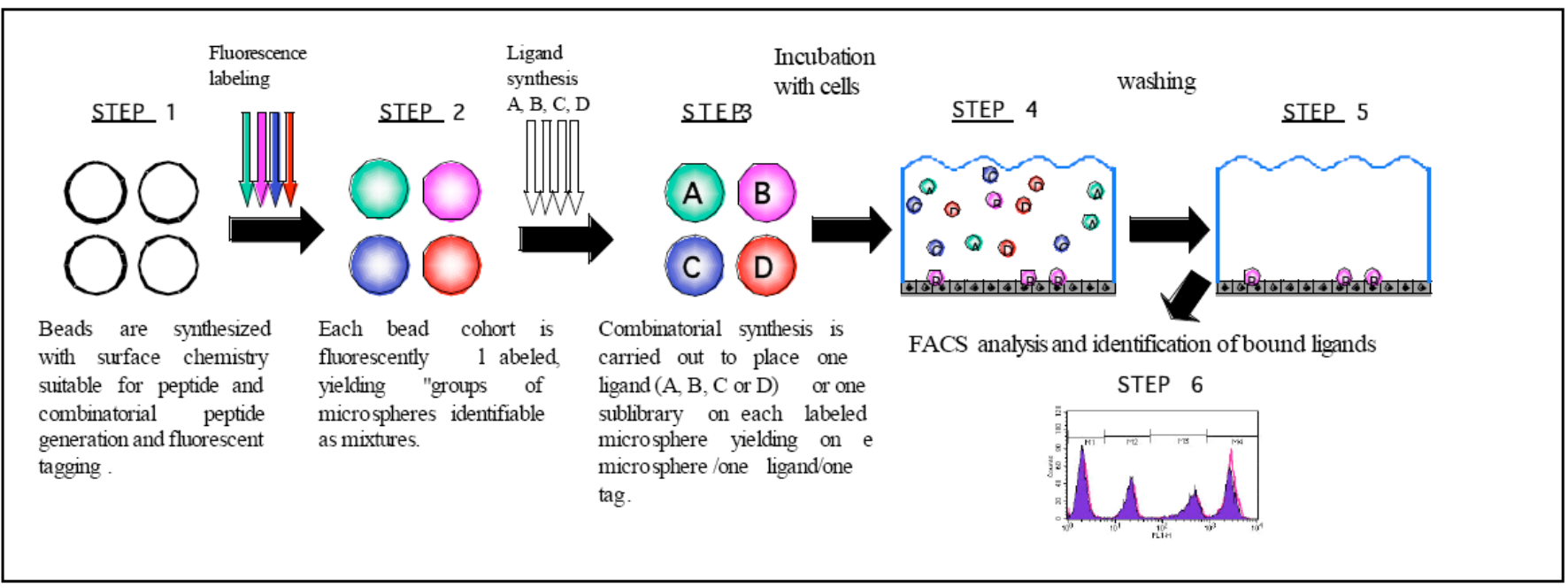

Fig. (1). Steps of live cell screening using a phage-like synthetic system. 
Table 1. Peptides Synthesized on $2 \mu \mathrm{m}$ Microspheres by Merrifield Method

\begin{tabular}{|c|c|c|c|c|c|}
\hline$\#$ & Structure & Sequence & HPLC & Calc. MS & Obt. MS \\
\hline \hline 1 & c-myc peptide & EQKLISEEDL & $16.01 \mathrm{~min}$ & 1202 & 1202 \\
\hline 2 & amyloid- $\beta$ & DAEFRHDSGYEVHH & $18.4 \mathrm{~min}$ & 1697 & 1697 \\
\hline
\end{tabular}

The peptides were synthesized in parallel wells of a 96 wells $0.45 \mu$ filter microplate using conventional peptide synthesis protocols (see materials and methods) [9-11]. After partial cleavage, the crude soluble products were analyzed by HPLC and mass spectroscopy confirming the good quality and the correct molecular weight of the expected peptides (see Table 1 for MS and supporting information for HPLC profiles).

Peptides were also characterized successfully while linked to the microspheres by an ELISA assay using specific antibodies (see materials and methods).

Fig. (2) discloses the ELISA obtained for a panel c-myc peptides synthesized on different batches of the microspheres using a monoclonal mouse anti-human c-myc antibody. The peptide was synthesized in seven parallel wells which were individually tested for binding of the specific antibody. Columns 1-7 show the binding of the antibody to different synthetic batches of the peptide as compared to a positive control of horseradish peroxidase reacted with the TMB substrate and negative controls where the c-myc was tested without removal of protective groups (protected) and for binding with the first antibody only, the second antibody only or no antibodies.

From these assays we conclude that the c-myc sequence synthesized on the microspheres is biologically functional. All the batches (1-7) responded to the antibody thus proving at once the robustness of the synthesis and the biological functionality of the sequence.

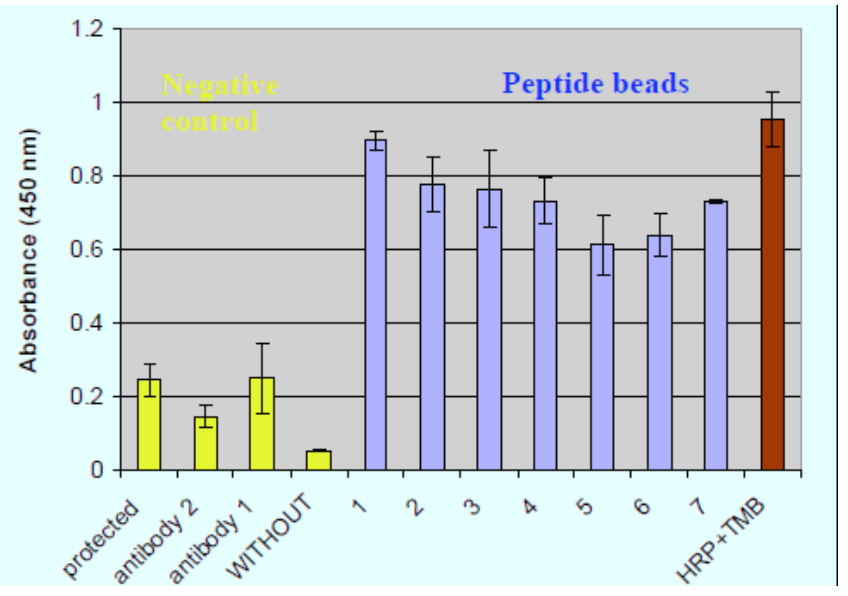

Fig. (2). Summary of ELISA results of 3 experiments on 7 separated wells of c-myc peptide microspheres, which were developed with monoclonal mouse anti-human c-myc antibody (blue columns), negative controls (yellow columns) and positive control (red column).

The situation was similar for the other sequence $\mathrm{N}$ terminal amyloid- $\beta$ that was synthesized on 3 parallel posi- tions and displayed specific binding to a rabbit (polyclonal) anti-human $\mathrm{N}$-terminal amyloid $\beta$ antiserum antibody using similar controls as for the c-myc sequence (see Fig. 3).

Overall, these results indicate that peptides can be reliably synthesized on mono-dispersed $2 \mu \mathrm{m}$ microspheres using classical Fmoc chemistry and that they can adopt conformations relevant for bio-recognition of antibodies. To our knowledge, these are the smallest particles ever used for a Merrifield solid phase synthesis of peptides [9]. The subcellular size of these microspheres rends them unique for applications to live cell screening where small molecules are synthesized and then screened directly while they are tethered on the microspheres in a live cell assay.

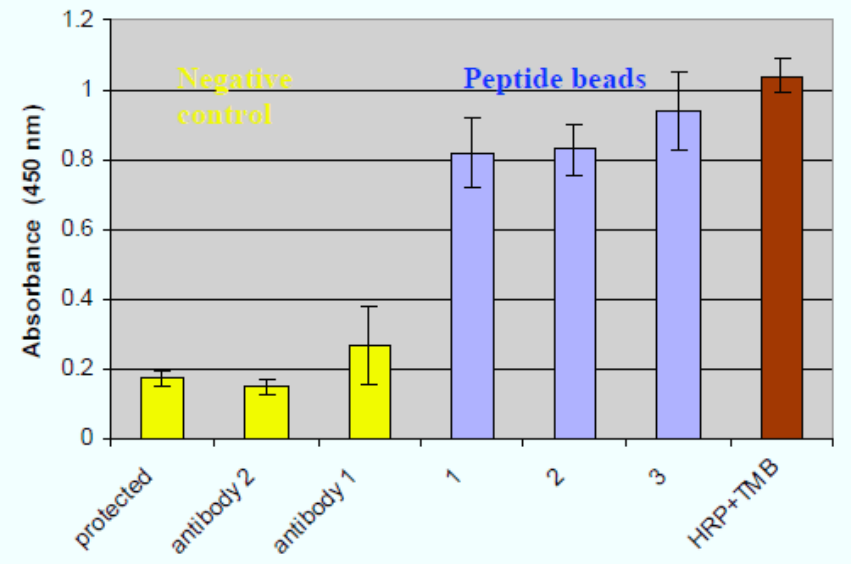

Fig. (3). Summary of ELISA results of 3 experiments on 3 separated wells of amyloid- $\beta$ peptide microspheres, which were developed with rabbit (polyclonal) anti-human amyloid $\beta \mathrm{n}$ terminal antiserum antibody (blue columns), negative controls (using the fully protected amyloid- $\beta$ peptide on microspheres and using only the secondary or primary anti-bodies, yellow columns) and positive control (secondary antibody incubated with TMB substrate, red column).

Combinatorial Peptide Libraries Synthesized on the Phage Like System can be Screened for Affinity to PC-3 Cells by a Flow-Cytometry Based Biological Assay

As shown before, the assay is based on the comparison of binding of a molecule (or sub-library) bound to a micropshere, MBMn ( $\mathrm{n}$ is the number of a specific ligand, member of a library composed of $n$ members), and a known ligand bound to a microsphere, KLBM defined as the positive calibration control. Each microsphere population bearing a different MBMn is labeled with a defined fluorescence level in a way that individual and different molecules or sublibraries can be unambiguously followed and quantified by flow cytometry. 
The relative amount of a specific MBMn in a mixture is defined relative to the KLBM standard. To calculate this, the total number of events representing the MBMn is divided by the total number of events representing KLBM (each event represents one microsphere and the overall number of events for MBMn or KLBM is represented by the corresponding peak in the histogram). The number of events is automatically calculated by the software of the flow-cytometer which can also calculate the \% of each population (each ligand or each sub-library) out of the total number of microspheres in the mixture. The data are automatically obtained in the form of a table containing the percentage of each member in the mixture (events of each population out of the overall events of the mixture). These percentages are placed in equation 1 to obtain a rank for each compound.

If the initial ratios $\left(\mathrm{MBMn}_{\text {initial }}: \mathrm{KLBM}_{\text {initial }}\right)$ are calculated by performing a FACS analysis of the starting mixture (prior to incubation with cells), we can rank the relative binding extent of each MBMn to cells by comparing the ratios of the bound microspheres obtained after incubation with cells and washings to the starting ratio. This relationship is easily expressed by equation (1), where KLBM and MBMn represent number of events detected for each type of microspheres (or their percentage in the mixture which is the same):

$\left(\mathrm{KLBM}_{\text {initial }} \mathrm{X} \quad \mathrm{MBMn}_{\text {bound }}\right) /\left(\mathrm{KLBM}_{\text {bound }} \mathrm{XMBM} \mathrm{n}_{\text {initial }}\right)=\mathrm{X}$

Equation (1)

In this way, the relative binding of different molecules of a library can be ranked. X larger than 1 shows higher binding of MBMn as compared to the KLBM positive standard, ratios lower than 1 indicate lower binding of MBMn compared to the KLBM positive standard. Overall, one can estimate if a given molecule or sub-library (MBMn) displays significant binding to a tested cell line as compared to the binding of a molecule (KLBM) known to have strong binding to the cell line. This process is especially interesting for finding molecules with strong affinity for specific cells without early knowledge of the cellular targets involved in the affinity. This is exactly the way phage display peptide libraries are evaluated.

The throughput of the new screening platform is limited by the number of different fluorescence levels that label the microspheres. To date the quantity of ligands that can be tested as mixtures is limited, we are able to introduce 6 levels, thus if one level is used for the positive calibration control KLBM, we can use mixtures of up to $5 \mathrm{MBM}_{(1-5)}$ at a time. However, it is possible to do better if we prepare combinatorial peptide libraries so that each member is a mixture of several peptides sharing a common sequence except for a specific position where a mixture of amino acids is applied, thus we can introduce point-mixtures and compare their affinity for the cells assuming that the difference in affinities will be induced by the convoluted position (we call this approach biased inverted positional screening).

\section{SYNTHESIS OF COMBINATORIAL INVERTED BIASED POSITIONAL LIBRARIES}

We choose to prepare a biased convoluted combinatorial library derived from the known peptide DUP-1 so that most of the positions in the native peptide DUP-1 remain untouched. In the biased library we exchanged each of two arginines in the native sequence by a mixture of 12 amino acids at a time (see Fig. 4). There are two rationales for these

\footnotetext{
DUP-1 H- Phe- Arg - Pro - Asn - Arg - Ala - Gln - Asp - Tyr - Asn - Thr $\cdot$ Asn $-\mathrm{NH}_{2}$ (KLBM)<smiles>[Li][Mg]</smiles>

Fig. (4). General strategy for biased positional libraries approach. 
exchanges: firstly, peptides containing arginine are sensitive to various endo-proteases, thus the use of a degradable peptide for tumor targeting is strongly disfavored: the convoluted sub-libraries might result, after deconvolution, in active and less degradable peptides. Secondly, arginine is, in many cases, involved in selective bindings by forming electrostatic interactions with target receptors through the guanidinium charged side chain, thus we can expect to affect significantly the binding affinity by removing arginine from the peptide. Therefore, two convoluted sub-libraries were synthesized on labeled microspheres as mixtures of 12 biased peptides in each sub-library. The biased libraries I and II were synthesized by the systematic introduction of a kinetic mixture of Fmoc-amino acids [12] at each of two arginine positions in the backbone of the peptide (see Fig. 4). The syntheses were performed using the general method described in materials and methods.

\section{Screening of Biased Combinatorial Libraries in PC-3 Cells}

The libraries I (MBM1) and II (MBM2) were screened in mixtures containing DUP-1 microspheres (KLBM). Each of the libraries and DUP-1 were synthesized on microspheres bearing different FITC fluorescence levels that allows optical evaluation with FACS.
We incubated a mixture containing libraries I, II and DUP-1 in a single experiment as duplicates. The histogram in Table 2 discloses the "initial" composition of the libraries (black plot) and "cell bound" composition of the libraries after incubation, washings and lysis (pink and green plots for two experiments). In order to rank the libraries we refer to equation (1) as explained above. Thus, analysis of results indicates a ranking value of 0.72 for MBM2 and 0.99 for MBM1. According with these results combinatorial library I (MBM1, Table 2, M1 peak) displays higher affinity for PC-3 cells as compared to library II (MBM2, Table 2, M3 peak). This result correlates with those obtained with separated mixtures of library I/DUP-1 and library II/DUP-1 (data not shown). Thus, library I (MBM1) was submitted to deconvolution for finding individual peptides with high affinity for PC-3 cells.

\section{Deconvolution of Library I and Combinatorial Screening of Groups of Individual Members}

The 12 deconvoluted peptides-microspheres were synthesized individually using the same general method and are summarized in Table $\mathbf{3}$ according to their unique fluorescence label and sets.

Each peptide is assigned with a singular MBMn value. Each set of MBM's +KLBM contains 4 non overlapping

Table 2. FACS Analysis of Microsphere Mixtures Composed of DUP-1(KLBM) and Biased Combinatorial Libraries I (MBM1) and II (MBM2): Black Histogram Initial Composition, Pink and Green Histograms: End Composition in Two Experiments After Incubation with PC-3 Cells (See Materials and Methods). The Table Gives the Ratio for Each Compound and Its Final Ranking. X= Mixture of 12 Amino Acids: A, N, Q, G, H, I, K, F, P, S, T, Y

\begin{tabular}{|c|c|c|c|c|c|c|}
\hline Name & Sequence & $\begin{array}{c}\text { FITC } \\
\text { label }\end{array}$ & Marker & $\begin{array}{c}\text { \% of } \\
\text { gated } \\
\text { initial }\end{array}$ & $\begin{array}{c}\text { \% of } \\
\text { gated } \\
\text { bound }\end{array}$ & $\begin{array}{c}\text { Rank } \\
\text { Equation } \\
\text { (1) }\end{array}$ \\
\hline \hline $\begin{array}{c}\text { DUP-1 } \\
\text { KLBM }\end{array}$ & FRPNRAQDYNTN & $0.2 \%$ & $\mathrm{M} 2$ & 17 & 19.4 & 1 \\
\hline $\begin{array}{c}\text { Library } \\
\text { MBM 1 }\end{array}$ & FXPNRAQDYNTN & $1 \%$ & $\mathrm{M} 1$ & 38 & 43 & 0.99 \\
\hline $\begin{array}{c}\text { Library } \\
\text { MBM 2 }\end{array}$ & FRPNXAQDYNTN & $0.04 \%$ & $\mathrm{M} 3$ & 44 & 36 & 0.72 \\
\hline
\end{tabular}

Table 3. Summary of Deconvoluted Peptide Sets from Library I. FOPNRAQDYNTN , $\mathrm{O}=$ one among 12 amino acids $\mathrm{O}=\mathrm{A}, \mathrm{N}, \mathrm{Q}, \mathrm{G}, \mathrm{H}, \mathrm{I}, \mathrm{K}, \mathrm{F}, \mathrm{P}, \mathrm{S}, \mathrm{T}, \mathrm{Y}$

\begin{tabular}{|c|c|c|c|c|}
\hline $\mathbf{0 . 2} \%$ & $\mathbf{0 . 0 4 \%}$ & $\mathbf{0 . 0 0 8 \%}$ & $\mathbf{0 . 0 0 1 6 \%}$ & Set number \\
\hline \hline Thr(MBM3) & DUP-1(KLBM) & Tyr(MBM2) & His (MBM1) & 1 \\
\hline Gln(MBM6) & DUP-1(KLBM) & Lys(MBM5) & Asn(MBM4) & 2 \\
\hline Gly(MBM9) & DUP-1(KLBM) & Ser(MBM8) & Ile(MBM7) & 3 \\
\hline Ala(MBM12) & DUP-1(KLBM) & Phe(MBM11) & Pro(MBM10) & 4 \\
\hline
\end{tabular}


Table 4. Histograms and Overall Ranking Obtained for Deconvoluted Library I FOPNRAQDYNTN Calculated Using Equation (1). M2= DUP-1 in All the Experiments. Purple Histograms: Initial Composition, Yellow Histogram: End Composition.

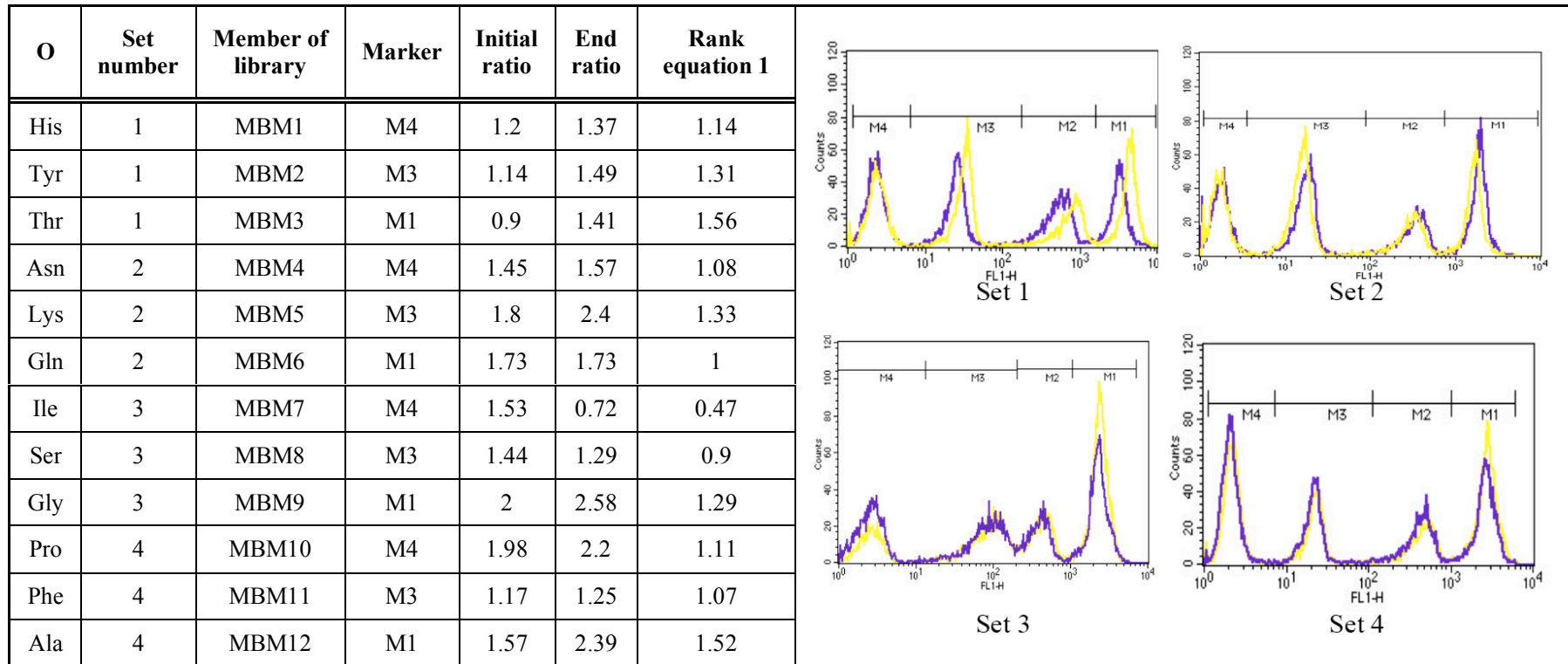

fluorescence intensity labels: 3 of them are populated by MBM's and one is always used for the control DUP-1microspheres (KLBM).

The FACS plots obtained for the different sets, as well as the ranks for the 12 peptides are disclosed in Table 4.

Results indicate that the peptides with the highest ranks are those containing threonine (DUP- $1_{(1-12)}{ }^{2} \mathrm{Thr}$ ) and alanine (DUP-1 $1_{(1-12)}^{2}$ Ala). We choose the peptide DUP- $1_{(1-12)}^{2}$ Ala for further validations.

\section{Validation Studies}

Validating the affinity of small molecules for an unknown target in vitro is of course impossible. However, it is possible to establish a semi-quantitative comparative binding analysis of small molecules in a live cell assay to evaluate the approximate extent of binding to specific cell types. Zitzman et al. [7] have already validated the binding of DUP-1 to PC-3 cells using a radioactive derivative of DUP-1 in the presence of increasing concentrations of unlabeled DUP-1. An IC50 of $1 \mu \mathrm{M}$ was thus obtained for DUP-1. Additionally, in the same work the binding of fluorescently labeled DUP-1 was observed qualitatively using confocal microscopy. To further demonstrate the reliability of the proposed screening technique, we performed a competitive binding assay on cells in suspension based on this work, using fluorescently labeled probes and FACS analysis [13]. In this assay, unlabeled molecules to be tested at different concentrations and fluorescently labeled DUP-1 at a given concentration are added to the cells and their fluorescence intensity, representing the amount of the known molecule bound, is tested by flow cytometry. It should be pointed out that with this method, full competition between the molecules and DUP-1 is not expected: the ranking obtained for each molecule as compared to DUP-1 is a way for evaluating the extent of binding and not necessarily a proof of full competition with DUP-1. Each molecule can bind to multiple cellular targets, some of them might be common, and if this is the case, competition binding can be qualitatively evaluated. We have developed an independent validation assay in our laboratory based on previous works $[1,13]$. Candidate ligands identified by the screening were individually synthesized and characterized in solution. Compound Rak-2, previously validated as having good affinity for PC-3 cells, was synthesized in a pegylated form to improve solubilization and analyzed together with the new peptide candidate. (FITC- ${ }^{13}$ Lys)DUP-1 $1_{(1-12)}$ standard peptide was incubated with PC-3 cells at a concentration of $1 \mu \mathrm{M}$ in the presence of different concentrations of non-labeled DUP-1, negative control peptide 15 -mer or ligand hits as previously shown [1]. The cells were analyzed by flowcytometry and the affinity was determined using the geometric means obtained from FACS plots at the different concentrations of ligands [13]. The displacement obtained by the specific candidate ligand was compared to that of the standard DUP-1 peptide. In this way it is possible to obtain a relative extent of affinity as compared to the standard ligand. Fig. (5) shows the validation results obtained for DUP- $1_{(1-12)}{ }^{2}$ Ala and as compared to the small organic molecule Rak-2 validated in previous studies.

In the experiments we compared the displacement of (FITC- ${ }^{13}$ Lys)DUP-1 $1_{(1-12)}$ fluorescence by non-labeled DUP-1 ( $\boldsymbol{D})$ and by a new peptide DUP- $1_{(1-12)}{ }^{2} \mathrm{Ala}(\boldsymbol{)})$ found to have high affinity to PC-3 cells in our screening or by a small organic Ugi molecule Rak-2 ( $\boldsymbol{\Delta}$ ) found to have good to $\mathrm{PC}-3$ cells using the same screening technique in a previous work. We can clearly acknowledge that the affinity range of DUP- $1_{(1-12)}{ }^{2} \mathrm{Ala}(>)$ is slightly higher than that of the native DUP-1 ( $\square$ ) and the affinity range of small molecule Rak-2 ( $\boldsymbol{\Delta}$ ) is slightly lower but similar to that of the native DUP-1. On the other hand, we do not observe reduction of the fluorescence of labeled DUP-1 in the presence of a large range of concentrations of the non-related 15-mer peptide WGLRALESRDWRYYF $(\bullet)$, meaning that this peptide does not compete with (FITC- ${ }^{13}$ Lys)DUP-1 $1_{(1-12)}$ 


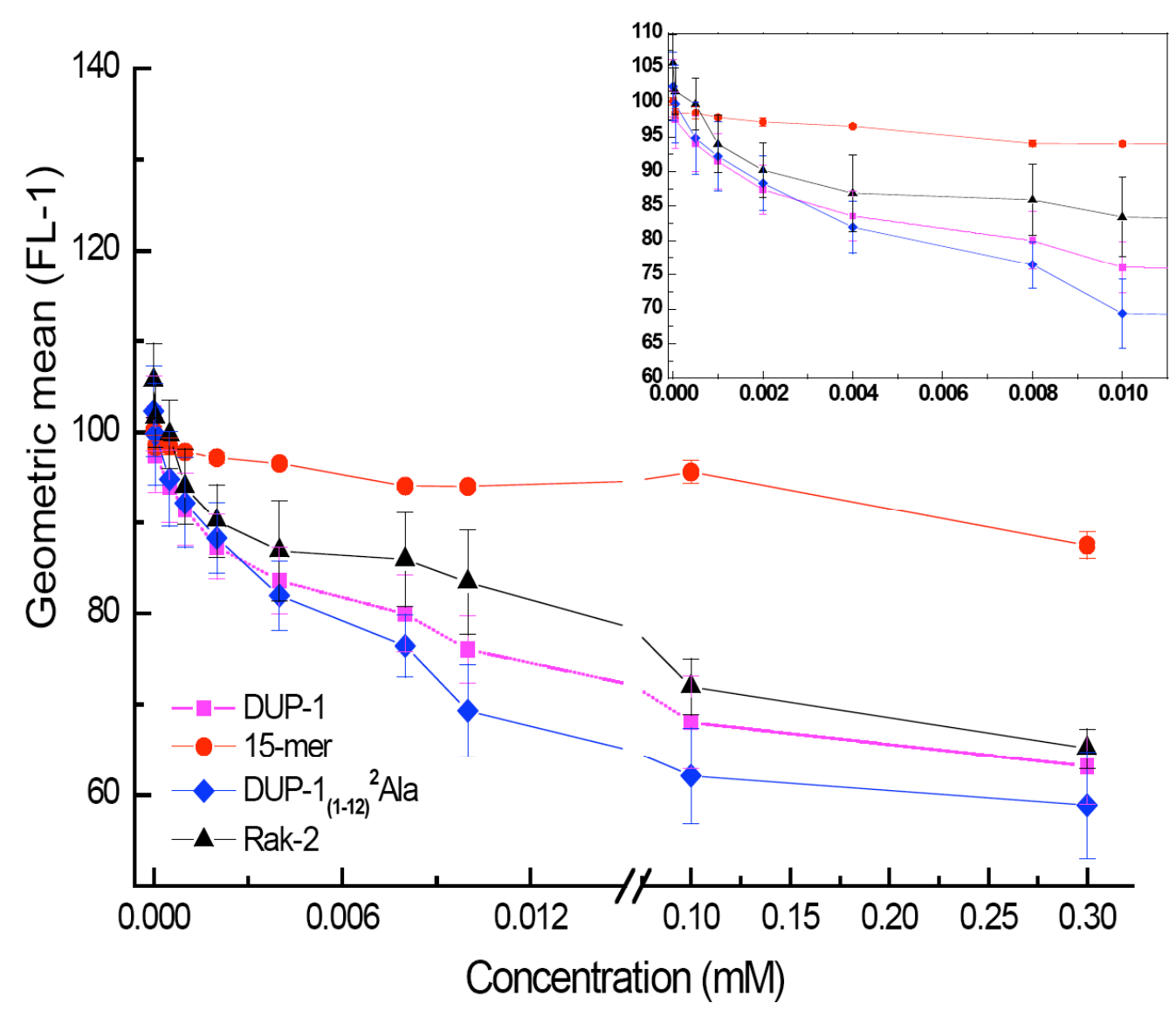

Fig. (5). Concentration dependent displacement of fluorescent-DUP-1 from PC-3 cells by unlabeled DUP-1 (positive control) ( $\square$ ), DUP-1 $1_{(1-}$ ${ }_{12}^{2}{ }^{2}$ Ala $(\bullet)$, small molecule Rak-2 $(\boldsymbol{\Delta})$ and 15-mer peptide (WGLRALESRWDRYYF) (negative control) $(\bullet)$ as measured by flowcytometry. Mean values \pm S.E.M., $n=3-5$ (materials and methods).

for binding to cells (negative control). Overall we have demonstrated that the peptide DUP- $1_{(1-12)}{ }^{2}$ Ala identified in the screening have good affinities to PC-3 cells as compared to control DUP-1 and the previously validated Rak- 2 small molecule.

\section{Intracellular Fate of DUP-1 ${ }_{(1-12)}{ }^{2}$ Ala}

Another independent way for demonstrating affinity for PC-3 cells and as a preliminary way for understanding the mechanism of interaction, is to observe the interactions of labeled molecules with cells using microscopy. We have incubated (FITC- ${ }^{13}$ Lys)DUP-1 $1_{(1-12)}$ and (FITC- ${ }^{13}$ Lys)DUP$1_{(1-12)}{ }^{2}$ Ala with PC-3 cells and compared their intracellular fate using confocal microscopy. The peptides were incubated at the same concentrations in living cells followed by two washings and addition of sulforhodamine B (SRB) (to a concentration of $1 \mu \mathrm{M}$ ) which labels the medium surrounding the cells, but is excluded from live cells. The FITC labeled peptides and SRB were imaged in an Olympus FV-1000/IX81 confocal inverted microscope, using $40 \mathrm{x} / \mathrm{NA}=0.9$ air objective. The excitation wavelengths were $488 \mathrm{~nm}$ for the FITC, and $561 \mathrm{~nm}$ for the SRB. The FITC was detected using a $505-545 \mathrm{~nm}$ emission filter, while a $585-615 \mathrm{~nm}$ barrier filter was used to detect SRB. FITC and SRB were imaged sequentially, to avoid crosstalk between the two fluorescence channels. A nonconfocal DIC transmitted light image was also acquired. The (FITC- ${ }^{13}$ Lys)DUP-1 $1_{(1-12)}$, (FITC- $-{ }^{13}$ Lys)
DUP- $1_{(1-12)}{ }^{2}$ Ala and non-treated cells images were acquired under the same acquisition conditions.

All image processing was done in Image $J$ [6]. The SRB images were thresholded using the Otsu automatic thresholding option within ImageJ. The resulting binary images were used to find the edges of the cells. The edges which were found are highlighted on the FTIC and SRB images. The dark areas are definitely within the cells, as these are areas from which SRB is excluded.

We verified that these areas are separated by at least two microns from the edge of the cell by checking addition $\mathrm{z}$ planes (data not shown).

The labeled peptide images were processed as follows. The 12 bit images were divided by 16 and then converted to 8-bit images without scaling, so as to avoid various auto scale functions which distorted the relative strength of the images. A rolling ball filter of radius 100 was used to remove slowly varying background. A linear contrast stretch which mapped 255 to 60 was applied to all of the images from the FITC channel. This last step was only done to make the images easily visible. The relative strength of the signals was not changed by this operation.

A confocal plane which definitely passed within the cell was chosen, by verifying that there were dark sections both above and below the selected plane. The edges of the cell at this level were found from the corresponding SRB image, 


$$
\text { (FITC- }{ }^{13} \text { Lys)DUP-1 } 1_{(1-12)}{ }^{2} \text { Ala } \quad \text { no peptide } \quad \text { (FITC- }{ }^{13} \text { Lys)DUP-1 } 1_{(1-12)}
$$

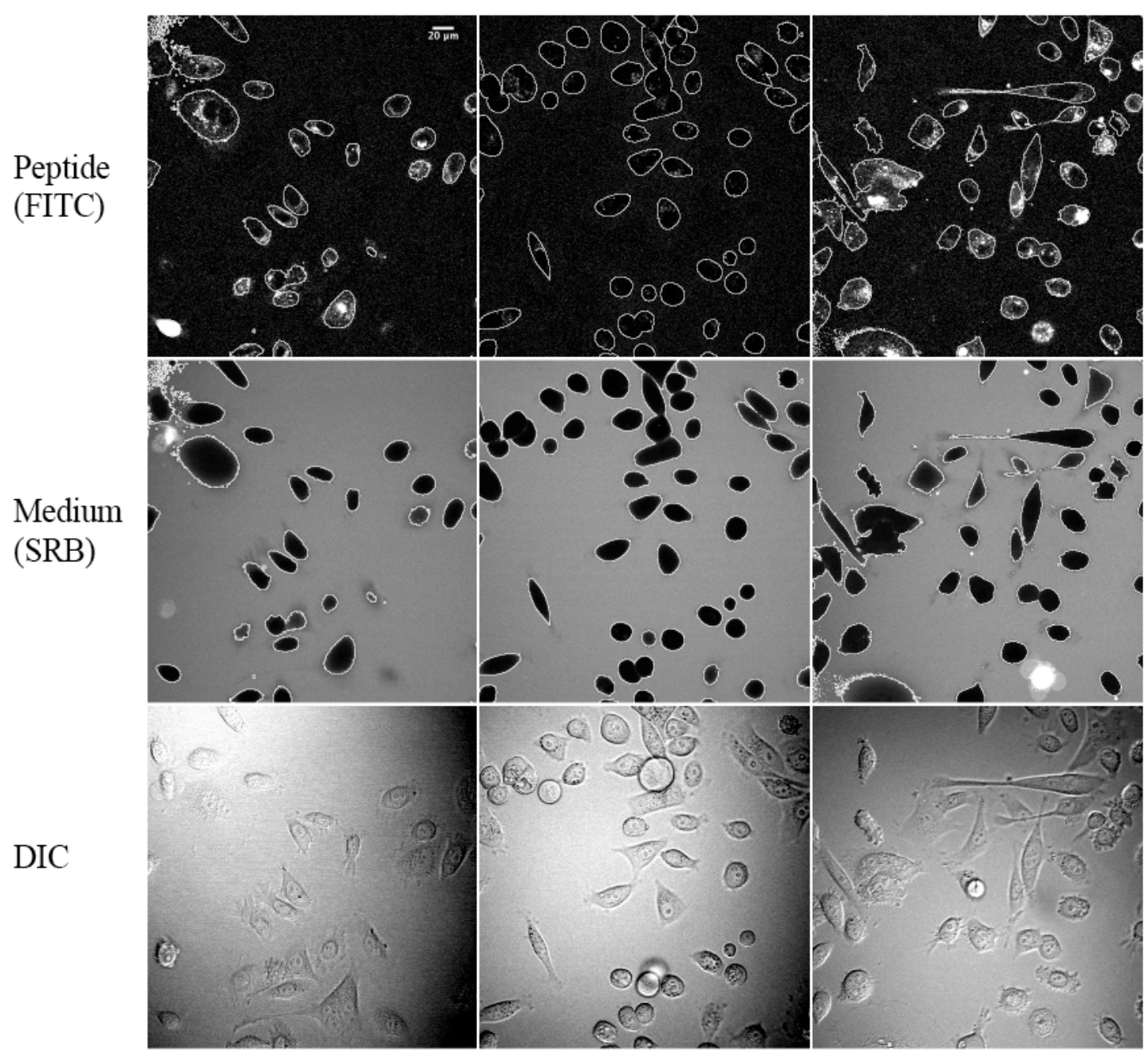

Fig. (6). Confocal images of PC-3 cell which were incubated with (FITC- ${ }^{13}$ Lys)DUP- $1_{(1-12)}{ }^{2}$ Ala, $\left(\right.$ FITC- ${ }^{13}$ Lys)DUP-1 $1_{(1-12)}$, or no peptide addition, as indicated. The cell culture medium contained about $1 \mu \mathrm{M}$ SRB. Top row: FITC channel, which images the labeled peptides. Middle row: SRB images, which shows the location of the interior of the cells. Bottom row: nonconfocal DIC images. The cell boundaries, as found from the SRB images by edge detection, are indicated in white on the FITC and SRB images (top two rows). See experimental section for acquisition conditions of confocal microscopy.

and these edges were overlaid onto the FITC channel images to show the cell locations.

Fig. (6) shows a typical result. The top row is the FITC channel, the middle row contains the SRB images, in which the cell interiors are dark in viable cells, and the bottom row are the corresponding DIC images. The DIC images are shown in Fig. (6) to indicate normal cell morphology, and to confirm cell location. The edges found from the SRB images do not correspond exactly to the DIC images of the cells, because the DIC images are not confocal.

The important point of Fig. (6), is that under similar acquisition conditions, there is easily visible incorporation of (FITC $-{ }^{13}$ Lys)DUP- $1_{(1-12)}{ }^{2}$ Ala and (FITC- ${ }^{13}$ Lys)DUP- $1_{(1-12)}$, while the non-treated cells show some auto fluorescence, but much lower signals than the cells which were incubated with the labeled peptides.
These results correlate and complement the validation results obtained by displacement of (FITC- ${ }^{13}$ Lys)DUP- $1_{(1-12)}$ by non-fluorescent DUP- $1_{(1-12)}{ }^{2}$ Ala disclosed in Fig. (5). There, we have already shown that non fluorescent DUP$1_{(1-12)}{ }^{2}$ Ala displaces the (FITC- ${ }^{13}$ Lys)DUP- $1_{(1-12)}$ peptide, while a non-fluorescent non-related peptide 15 -mer does not compete with the DUP-1 so far. Finally, our microscopy results correlate and complement those obtained by Zitzmann [7] for FITC-DUP-1 in a previous work.

\section{CONCLUSIONS}

We have extended the application of a fully synthetic phage-like system used for live-cells screening of mixtures of ligands to screening of combinatorial peptide libraries.

The robustness of the synthesis was demonstrated by HPLC and MS analysis of partially cleaved peptides as well as by biological affinity recognition using appropriate 
antibodies in ELISA assays. The $2 \mu \mathrm{m}$ particles used here are the smallest particles ever used in Merrifield synthesis to our knowledge and their interest lie in their sub-cellular size that allows screening in a live cell assay. The evaluation of combinatorial libraries and their deconvolution that resulted in the identification of peptide DUP- $1_{(1-12)}{ }^{2}$ Ala with good affinity for PC-3 cells and its validation using an independent binding assay and confocal microscopy, represents an extension of the concept of "synthetic phage-like" systems using sub-cellular sized microspheres suitable both for peptide synthesis and biological screening. These "synthetic phage-like systems" were used here on cell cultures and opened the gates for future high throughput in live cells/in vivo screening. The advantage of the presented system is that non-peptide molecules and also combinatorial libraries might also be synthesized and screened as mixtures of subcellular sized microspheres, in contrast to phage display strategy that screens and identifies only natural peptides of a sequence no longer than 12 amino acids [2-4]. During the last years another cell based combinatorial screening technique using microspheres of $100-500 \mu \mathrm{m}$ called "rainbow beads" has been described [14] for screening adhesion of cells to "giant" microspheres and some effects of this adhesion on signal transduction has been shown [15]. The main limitation of the rainbow system is the size of the microsphere which prevents any interaction of cells with the microspheres other than adhesion. The size of our system allows, in principle, not only to study the adhesion of sub-cellular sized modified microspheres to live cells but also their internalization and eventual intracellular fate mediated by the molecules synthesized on their surface. Although there is still a long way to go for adapting this system to high throughput in vivo screening, another step of feasibility has been demonstrated in relevant cultured cells and validated by an external binding assay and microscopy. The peptide identified here is being the object of further studies aimed at elucidating the mechanism of interaction with cancer and somatic cells.

\section{ACKNOWLEDGEMENTS}

We are indebted to Mr. Uri Karo for expert advice and help in flow-cytometry, to Dr. Hugo Gottlieb and Dr. Rachel Persky for structural analysis, and to Dr. Tamara Byk for expert advice in FACS and cell culture. We would like to express our sincere gratitude to the Israel Council for Higher Education for supporting the Converging Technologies Fel- lowship and BIU President Scholarships to Raz Khandadash. This work was supported by the Israel-USA Binational Foundation (BSF 1998378), AFIRST Israel/France (program of the French Ministry of Foreign Affairs and the Israeli Ministry of Sciences), and The Marcus Center for Medicinal Chemistry of Bar Ilan University.

\section{REFERENCES}

[1] Byk G, Partouche S, Weiss A, Margel S, Khandadash R. Fully synthetic phage-like system for screening mixtures of small molecules in live cells. J Comb Chem 2010; 12: 332-45.

[2] Smith GP, Petrenko VA. Phage display. Chem Rev 1997; 97: $391-$ 410.

[3] Felici F, Castagnoli L, Musacchio A, Jappelli R, Cesareni G. Selection of antibody ligands from a large library of oligopeptides expressed on a multivalent exposition vector. J Mol Biol 1991; 222: 301-10.

[4] Iannolo G, Minenkova O, Petruzzelli R, Cesareni G. Modifying filamentous phage capsid: limits in the size of the major capsid protein. J Mol Biol 1995; 248: 835-44.

[5] Sanchez-Martin RM, Muzerelle M, Chitkul N, How E, Mittoo S, Bradley M. Bead-based cellular analysis, sorting and multiplexing. ChemBioChem 2005; 6: 1341-5.

[6] Collins TJ. ImageJ for microscopy. BioTechniques 2007; 43: 25 30 .

[7] Zitzmann S, Mier W, Schad A, et al. A new prostate carcinoma binding peptide (DUP-1) for tumor imaging and therapy. Clin Cancer Res 2005; 11: 139-46.

[8] Yang R, Prorok M, Castellino FJ, Weliky DP. A trimeric HIV-1 fusion peptide construct which does not self-associate in aqueous solution and which has 15-fold higher membrane fusion rat. J Am Chem Soc 2004; 126: 14722-23.

[9] Merrifield RB. Solid phase peptide synthesis. I. The synthesis of a tetrapeptide. J Am Chem Soc 1963; 85: 2149-54.

[10] Castro B, Dormoy JR, Evin G, Selve C. Peptide coupling reagents. IV. N-[Oxytris(dimethylamino)phosphonium]benzotriazole hexafluorophosphate. Tetrahedron Lett 1975; 16: 1219-22.

[11] Carpino LA. 1-Hydroxy-7-azabenzotriazole. An efficient peptide coupling additive. J Am Chem Soc 1993; 115: 4397-8.

[12] Herman LW, Tarr G, Kates SA. Optimization of the synthesis of peptide combinatorial libraries using a one-pot method. Mol Divers 1997; 2: 147-55.

[13] Ziemek R, Brennauer A, Schneider E, et al. Fluorescence- and luminescence-based methods for the determination of affinity and activity of neuropeptide Y2 receptor ligands. Eur J pharmacol 2006; 551: 10-8.

[14] Luo J, Zhang H, Xiao W, et al. Rainbow beads: a color coding method to facilitate high-throughput screening and optimization of one-bead one-compound combinatorial libraries. J Comb Chem 2008; 10: 599-604.

[15] Kumaresan PR, Wang Y, Saunders M, et al. Rapid discovery of dead ligands with one-bead-two-compound combinatorial library methods. ACS Comb Sci 2011; 13: 259-64. 